DOI: 10.11606/issn.2238-3867.v16i1p92-104

sala preta

ppgac

Dossiê Performatividades Originárias

\title{
As casas e os corpos em manifestações expressivas tradicionais, sagradas e profanas na região do Distrito Federal e
}

\section{seu entorno}

Houses and bodies in traditional, sacred and profane expressive manifestations in the Federal District region and its surroundings

Jorge das Graças Veloso

Jorge das Graças Veloso

Professor adjunto III da Universidade de

Brasília (UnB), ator, diretor e dramaturgo

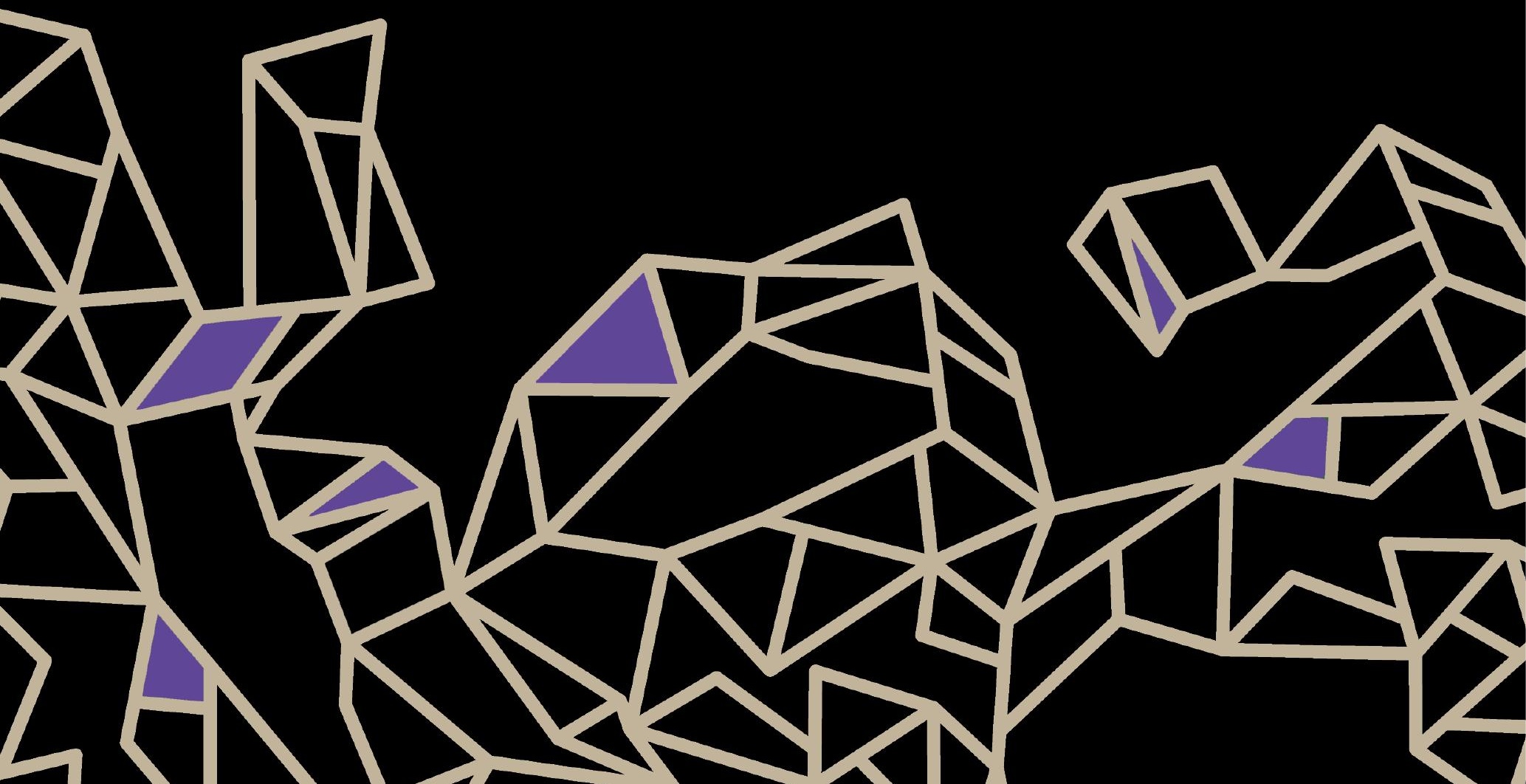




\section{Resumo}

Este artigo trata de uma reflexão acerca de pesquisas que visam, por registro e análises sobre tradições de Brasília e sua vizinhança, discutir, partindo do universo teórico da Etnocenologia, o que poderiam ser denominadas duas memórias brasilienses. Uma, recente, produzida a partir de narrativas que se consolidam desde a utilização primordial do chamado "Sonho de Dom Bosco," e outra, antiga, localizada em manifestações expressivas tradicionais, sagracionais ou não, que ocorrem tanto no quadrilátero do Distrito Federal quanto em seu entorno. Mais que demonstrar um sentimento de pertença a determinado grupo, esses ritos, entretanto, são uma mobilização que se volta para a manutenção, ou mesmo a (re)criação, de práticas para que os sujeitos desses mesmos grupos possam dizer que a elas pertencem.

Palavras-chave: Etnocenologia, Tradições, Memória brasiliense.

\section{Abstract}

This article reflects on researches that aim to discuss, by registration and analysis of the traditions of Brasília and its vicinity and based on the theoretical universe of Ethnoscenology, what could be called two Brasilia's memories. One of them isrecent, produced from narratives that are consolidated since the prime use of the so-called "Dream of Dom Bosco," and the other is ancient, found in traditional, sacred and profane expressive manifestations, which occur both in the quadrangle area of the Federal District and in its surroundings. These rituals, more than demonstrating a sense of belonging to a particular group, are a mobilization for the maintenance, or even the (re)creation, of practices so that the subjects of these groups can say that they belong to them.

Keywords: Ethnoscenology, Traditions, Brasília's memory.

Lá ia eu, pelas estradas de cascalho recém-restauradas, nas terras de Joaquim Domingos Roriz, naquele dia de maio, em mais um dos incontáveis giros da Folia do Divino, no meio rural do Novo Gama. Nos tempos de Amarildo Meireles, e antes ainda, nos giros comandados por Ofir Mulato, a fazenda do ex-governador do Distrito Federal, 
costumeiramente, era um dos lugares de pouso do cortejo precatório, votivo e rogatório, realizado, desde tempos imemoriais, pelos sítios e possessões da antiga vila, depois cidade de Santa Luzia, atual Luziânia, Goiás. Como sempre faço em minhas pesquisas, iniciadas em 2002, acompanhando o giro, mais uma vez parei no alto de um morro, de onde pretendia fotografar os cavaleiros com as bandeiras. E foi ali, olhando para o outro lado de uma ponte localizada no pé da serra que acabara de subir, que tive a visão. Descia pela estrada que vinha das bandas da Represa Corumbá IV, uma grande bola de poeira subindo dos cascos de mais de uma centena de cavalos, como se fosse um grande manto cobrindo a procissão. Como que cortando o translúcido da cortina de pó que subia ao céu do Divino Pai Eterno, lá vinha a bandeira. E ali, parado, fiquei não sei por quanto tempo, como se ouvisse de novo as palavras de Mestre Eurico, numa longínqua alvorada na casa de Tonhe de Zé de Orídio, em 2002.

E dá licença, luz, bom-dia, vou cuidar da devoção

Vou pedir o Pai Eterno, pra fazer a invocação

E pedir o apostlo São Pedro, que da Glória é o chaveiro

Que abriu a porta do céu, pra sair o mensageiro.

E vou pedir o Pai Eterno, o vosso Sagrado Manto

E Ele é quem tem os poder, de arvorar o Esprito Santo.

E fiquei, tomado pela imagem da procissão, vendo passar cada um dos cavaleiros que seguiam Mestre Rodrigo Meireles e Mestre Antonio Geraldo, alferes das bandeiras nesse ano. De repente, sem que eu percebesse sua chegada, dei-me conta da presença de um dos foliões, parado a meu lado, como se tentasse compreender o que tanto chamava minha atenção. "Cê tava firmando a poeira levantada pela tropa?", perguntou ele. Só aí eu percebi que não tinha feito nenhuma fotografia daquela imagem que tanto me arrebatara. E, pensando em Mestre Eurico e seu cantorio da arvorada, lembrei-me de uma construção imagética que havia feito durante minhas pesquisas passadas.

Parodiando as palavras do mestre que invoca a divindade, por essa construção, imagino o apóstolo São Pedro, que da Glória é o chaveiro, abrindo as portas do céu para sair o mensageiro. E desce do alto uma pequena pomba branca que pousa nas duas bandeiras vermelhas e se transmuta, 
tornando-se ela os próprios pedaços de pano, onde já estava pintada, e ali habita por todo o tempo do cortejo. Num milagre do mistério epifânico (DURAND, 1988), além de transformar-se nos próprios estandartes, faz com que um grande manto sagrado, imaginário, em forma de cúpula, se estenda por sobre o grupo. E aí, eu, pesquisador/pesquisado, permito-me comungar com o que pensam os outros foliões, para quem essas bandeiras percorrem todo o trajeto de seus giros como se, de forma simbólica, estivessem cobertos por aquela grande bolha santificada. O que percebo, nas falas dos companheiros, é um sentimento de que, sob o manto do Divino Espírito Santo, estendido sobre o que eles chamam de companhia, estão protegidos de todos os males. Dizem que esse espaço sagrado, apartado de um mundo profano (ELIADE, 2001), lá de fora, é um lugar de agradecimento, pela vida e pelos milagres recebidos durante $o$ ano. $E$ dentre os companheiros, foi como se ouvisse também as palavras de Mestre Geraldo da Silva Rosa (2003):

Então foi Santos Reis, muntado nos animais, né, fazer essa visita [ao menino Jesus na manjedoura], foi a premera fulia qu'ixistiu, premera fulia. Aí fizero a visita lá, né, e aí eles foram voltar, né, e aí vai. Quando Jesus tava já grande, já escolheu os apóstolo, foi a segunda fulia, de Jesus e os apóstolo, segunda fulia, que é essa que nós estamos comandando hoje, né, aí é a segunda fulia, Jesus e os apóstolo. Quando chegava lá na frente da casa, batia um zabumbo, né, aí avisando que elas ia chegando, pro povo num assustar, e aí chegava com os apóstolo [...]

A primeira ideia que me vem é a de que, assim falando, Mestre Geraldo transmite o sentimento de que gostaria que cada folia fosse considerada como substituta das peregrinações de Jesus Cristo e seus apóstolos pela Terra. Então existiria nesses cortejos, na contemporaneidade, em seus aspectos precatórios, uma ligação ancestral com o que ele chama de "premera fulia qu'ixistiu,' aquela em que o Mestre Guia teria sido o próprio Filho de Deus. E me vem, também como se ocorresse outra milagrosa epifania, a imagem de um grupo cada vez maior de homens, vestidos em suas túnicas bíblicas, a andar pelos desertos de uma Palestina esvanecida pelo tempo e seus eternos conflitos. Também ali, de desérticas terras ressequidas pelo sol escaldante, sobe uma grande nuvem de poeira, construindo a bolha sagrada que protege os andarilhos. Como nas folias de hoje, imagino um sem número de curiosos 
jovens que acompanham os mestres de novas ideias. Sequiosos por conhecer os segredos das palavras de cada um daqueles pregadores, sonham que num dia futuro, quem sabe, ocuparão seus lugares.

Ainda pensando nas palavras de Mestre Geraldim, como todos na companhia o chamam, olhei para o leste e me deparei com outra imagem de cúpula. Não sei por que, mas toda cidade vista de longe, para mim, parece coberta por uma grande redoma, como a visão que tenho da bolha que segue a folia pelo giro. E lá estava Brasília, ao longe, com seus mistérios esotéricos, seus discursos acadêmicos, suas falas intelectuais. A Brasília que aqui me trouxe. E ali, no alto de um monte distante, continuei a pensar.

$\mathrm{E}$ me veio à mente um texto profético, o sonho de Dom Bosco, inúmeras e repetidas vezes utilizado na construção de um discurso mítico sobre essa cidade, chamada por muitos de encantada. "Quando se vierem a escavar as minas escondidas em meio a estes montes, aparecerá aqui a terra prometida, onde correrá leite e mel. Será uma riqueza inconcebível” (SONHO, 2014). Mas se falar de palavras menos passíveis de interpretações outras já é difícil, o que pensar do que disse o sacerdote italiano, tantas e tantas vezes citado na quase totalidade da produção bibliográfica sobre a nova já quase velha capital do Brasil? Pensar nessa construção imagética, de uma cidade em que há leite e mel alimentando a todos, me faz sempre refletir que essa é a potente simbologia progressista de idealização de um mundo novo. Um lugar projetado, onde a maior constatação será a de que o futuro é sempre visto como melhor. Por esse pensamento, é lá, nos grandes espaços (como as avenidas brasilienses), símbolos de busca da liberdade, idealização da beleza do novo, das promessas de mudança, enfim, no devir desse eldorado, que está a salvação. Como o foi em tempos mais remotos, quando, em viagens de colonização, povos de Europa se aventuraram em mares bravios. Buscavam diferentes espaços para suas ideias e suas vidas, para seus futuros.

Porém, ainda pensando sobre a bolha simbólica que cobre a capital do Brasil, apesar de construída sob a égide das ideologias modernistas, a constatação é de que ela está encravada na chamada pós-modernidade. $E$ esse é um tempo em que, em percepções urbanas de mundo, não vicejam discursos hegemônicos, pois os mandamentos maiores dos dias de hoje pregam exatamente o contrário. São discursos que reconhecem na alteridade, na 
divergência como princípio de complementaridade, na diversidade de vozes, o construto de outra maneira de bem viver. Metaforicamente, porém, não estamos diante de um conflito. Não é a escolha entre apreciar a grandiosidade panorâmica de um jardim inglês, ou o apelo a todos os sentidos, provocado por um jardim japonês. Em verdade, a noção que hoje temos, nessas ambiências, é a de que os dois se complementam.

Entretanto, voltando aos sonhos progressistas, em Brasília, e sobre Brasília, eu quero falar é de quem, nos seus espaços grandiosos e maravilhosos, e em seus arredores, não aceitou as novas pregações de hegemonia. Ou de muitos que aceitaram de outra forma, por outros caminhos, por outros andares. Esses tiveram outros deuses, outros ídolos, outras imagens. E aí surgem outras religiosidades, candomblés, umbandas, daimes, e diversos esoterismos de toda espécie, e também a diversidade avassaladora das múltiplas estéticas que conduzem as musicalidades, as visualidades e a cena dessas ambiências. E mesmo outros muitos se apegaram, mais e mais, a suas crenças anteriores a essa imposição de um novo Deus Uno. Não aceitaram o já velho iluminismo que deveria ser uma nova onisciência, uma nova onipresença, uma nova onipotência, representadas pelo ideal de revolucionárias cidades, desde os Congrès Internacionaux d'Architecture Moderne (CIAM) ${ }^{1}$. No caso, uma verdade ditada por quem acreditava saber o que é melhor para o outro, num outro movimento de colonização, como o diz textualmente Lúcio Costa (1980):

Trata-se de um ato deliberado de posse, de um gesto de sentido ainda desbravador, nos moldes da tradição colonial. [...] Nasceu de gesto primário de quem assinala um lugar ou dele toma posse: dois eixos cruzando-se em ângulo reto, ou seja, o próprio sinal da cruz. (p. 51-52)

Não nos esquecendo de que foi esse o pensamento criador dos traçados de uma Brasília modernista, que não conseguiu se consolidar como tal.

1 Os Consgrès Internationaux d'Architecture Moderne (CIAM) se constituíram, de 1928 até meados da década de 1960, no mais importante fórum internacional de debates sobre a arquitetura moderna. Tinham como premissa a transformação social, ou seja, a de que a arquitetura e o urbanismo modernos seriam os meios para a criação de novas formas de associação coletiva, de hábitos pessoais e de vida cotidiana. $\mathrm{O}$ trabalho de James Holston, A cidade modernista: uma crítica de Brasília e sua utopia (1993) é bastante esclarecedor de como os CIAM, que tiveram em Le Corbusier seu nome de maior excelência, propuseram-se a mudar o mundo. 
Paradoxalmente, muitos desses, resistentes, que acreditam não precisar entregar seus destinos a outrem, persistem na busca de um pensar antagônico. E, na contraposição às pregações de progresso, preconizadas pelo arquiteto da nova capital, permanecem ou reinventam a sua fé, apegando-se a práticas estético-religiosas utilizadas no que foi a primeira ideia colonialista, a da invasão europeia no século XVI. E na grandeza dessa contradição, esse é o lugar, essa é a imagem, esse é o elo.

Esse discurso, tão bem explicitado na fala de Lúcio Costa, é feito com a aparente deliberação de apagar qualquer resquício de uma memória antiga, das culturas que prevaleciam nas regiões onde Brasília se implantou e vive suas tensões cosmopolitas. O mais interessante de tudo isso é que, se fizermos uma pesquisa nas redes virtuais de nosso tempo, iremos encontrar sítios e mais sítios que falam de uma Brasília mística em todas as correntes do pensamento. Desde textos totalmente esotéricos, passando por pastores evangélicos das novas tendências pentecostais, até dissertações e teses abrigadas nos mais respeitados programas de pós-graduação de diversas universidades. Desde egiptólogos até sociólogos da mais reconhecida atuação.

Assim, pode ser visto na rede mundial de computadores (internet) um conjunto de imagens produzidas a partir de princípios que colocam a capital modernista do Brasil, verdadeira obra de arte, como sendo uma perfeita reprodução espiritualista da cidade egípcia de Akhetaton (Figura 1) São formulações que se complementam na junção da ordem dos esoterismos que povoam um sem número de grupos encontráveis no Distrito Federal. Complementaridade essa, representada no campo acadêmico desde os estudos de mestrado de lara Kern, publicados no livro De Aknaton a JK: das pirâmides a Brasilia (1984), até Um estudo sobre a identidade mística de Brasilia - DF, de Janaína Mourão Freire e Dante Flávio da Costa Reis Júnior (2011). 

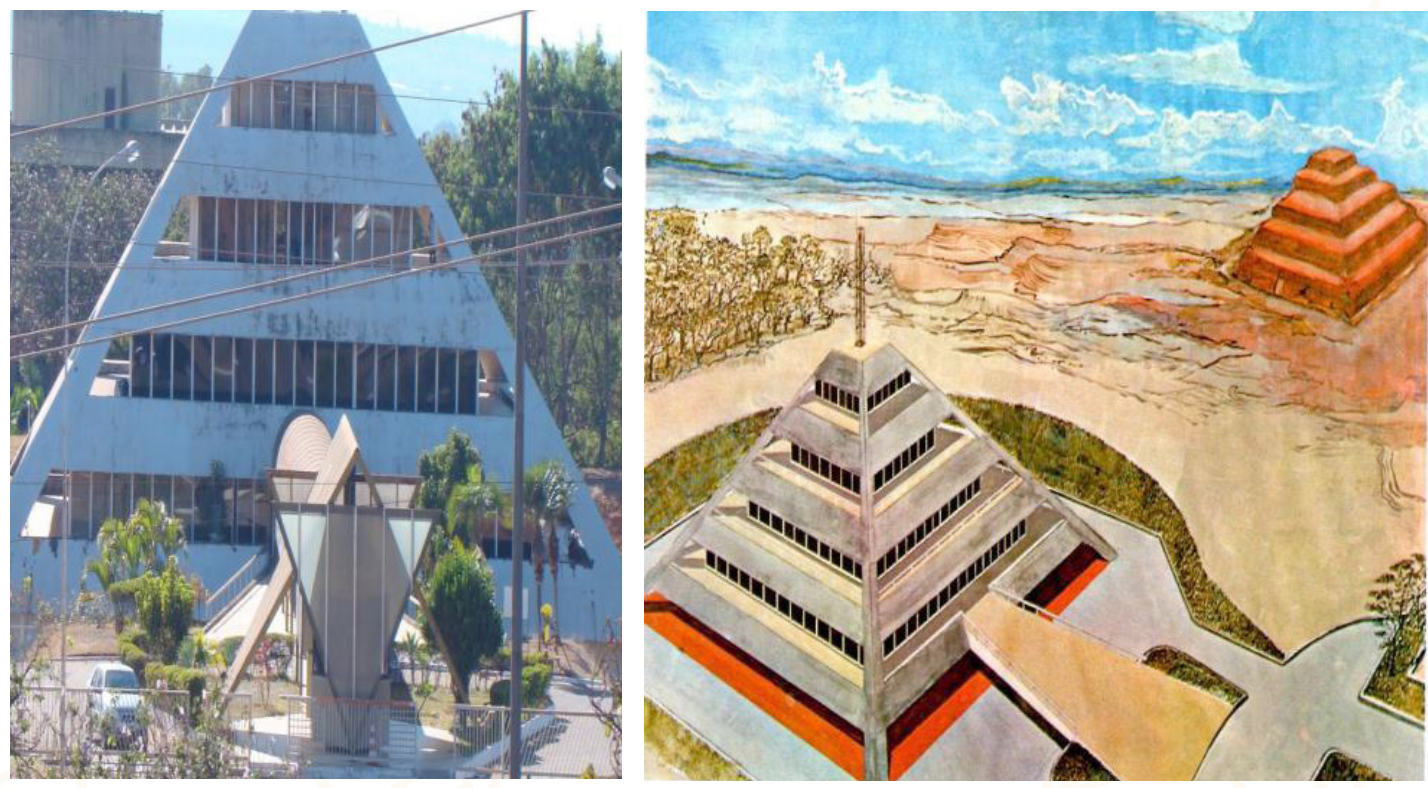

Figura 1 - Como exemplo de uma relação direta de Brasília com a cidade sagrada de Akhetaton, no antigo Egito, edifício da Companhia Energética de Brasília (CEB). Fotos: Pedro Paulo Rosa e na pintura de Byron de Quevedo.

Ainda no campo das academias, em 1997, Deis Siqueira e Lourdes Bandeira (1997) afirmavam que

[...] pretende-se refletir o quanto - ou como - é possível perceber relações e interações existentes entre a dimensão do sagrado e a espacialidade em Brasília, que foi fundada a partir de uma interação entre as dimensões do místico e do mítico. (p. 235-236)

Ora, se analisarmos essa construção a partir dessas ambiências mítico-mística-espaciais, perceptíveis nas citações acima, veremos que, por mais condescendentes que queiramos ser, não teremos como fugir do ideal hegemônico daqueles que dizem ser Brasília uma "caixa de cultura que caiu num espaço vazio". Por esse prisma, nas memórias recentes da nova capital se localiza, permanentemente, o princípio ideológico de "apagamento" da outra memória, a antiga, das pessoas comuns que aqui habitavam antes de sua criação.

Existe, porém, uma diferença fundamental entre as duas memórias. Enquanto a recente, mesmo falando de crenças, cola na nova capital um ideal esotérico pela perspectiva arquitetônica, onde a fé das pessoas se traduz em monumentos, na outra, a antiga, essa fé permanece nos corpos dos chamados devotos. 
Assim, eu gostaria também de citar algumas imagens de manifestações expressivas tradicionais que, a despeito do discurso modernista de apagamento do passado da região, insistem em permanecer. Começando por essa questão que me desperta maior interesse: o discurso de fé feito prioritariamente por corpos em estados alterados. Se olharmos o discurso do esotérico, encravado na modernidade da memória recente, advinda do sonho de Dom Bosco, veremos traçados arquitetônicos, edificações, lugares... Mas ao olhar para as manifestações tradicionais, das memórias antigas, o que veremos serão corpos em estado alterado, mostrando sua fé na teatralidade e na performatividade de seus rituais.

É dessa forma com as Procissões do Fogaréu, por exemplo. Em Luziânia, cidade goiana a sessenta quilômetros de Brasília, surgiu nos últimos anos um desses cortejos localizados na Semana Santa (Figura 2). Essa procissão, que tem sua maior expressão na cidade de Goiás, antiga capital do estado homônimo, representa o momento em que Jesus Cristo é perseguido até quando ele recebe o beijo de Judas Iscariotes, sendo em seguida preso e conduzido àqueles que irão realizar seu julgamento. Nela, o que vemos? Corpos em estados alterados de comportamento, atuando para uma plateia a cada ano maior e mais integrada ao rito espetacular. Um dos aspectos interessantes desse grupo de Luziânia é o fato de que ele, cada vez mais, tenta espetacularizar seu ritual. Sobre isso posso citar o projeto de seus organizadores, que vem sendo trabalhado junto a fiéis mais resistentes, de acrescentar, na procissão, bonecões similares aos bonecos do carnaval de Olinda, em Pernambuco.
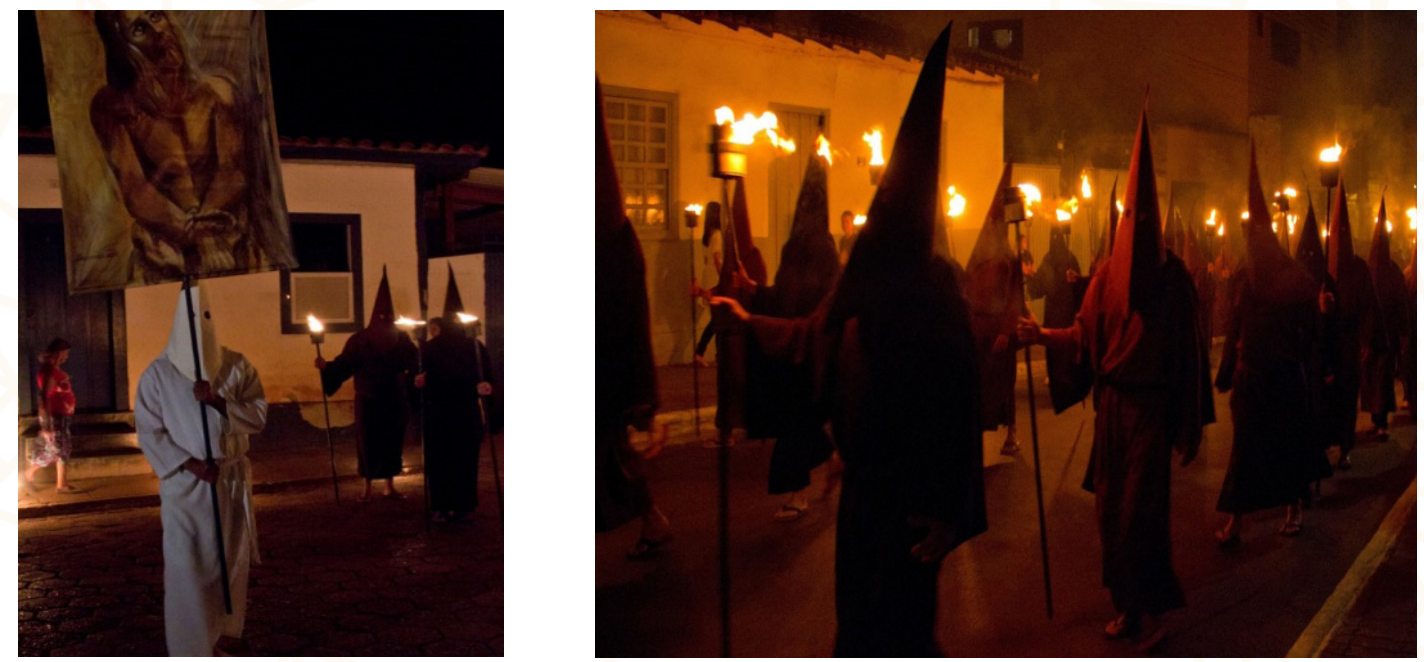

Figura 2 - Procissão do Fogaréu em Luziânia. A fé incorporada.

Foto: Tiago Veloso Machado (2011). 
Outra manifestação expressiva importante nas tradições da região vem de Paracatu, em MG, a aproximadamente 200 km de Brasília. Lá, naquela cidade mineira, permanecem comunidades que fazem as caretadas de São João (Figura 3). É um ritual ligado aos festejos juninos, representado durante 24 horas, ininterruptas, entre a manhã do dia 23 e a manhã do dia 24 de junho, nas comemorações dos festejos em homenagem ao santo. A característica principal desse ritual é: um grupo de homens cobre totalmente seus corpos, com roupas coloridas e máscaras, e formam pares que representam casais. E, durante essas 24 horas, eles vão de casa em casa, cantando, dançando, rezando e, nos mesmos moldes das folias, recebendo em troca comida, bebida e espaço para sua festa.
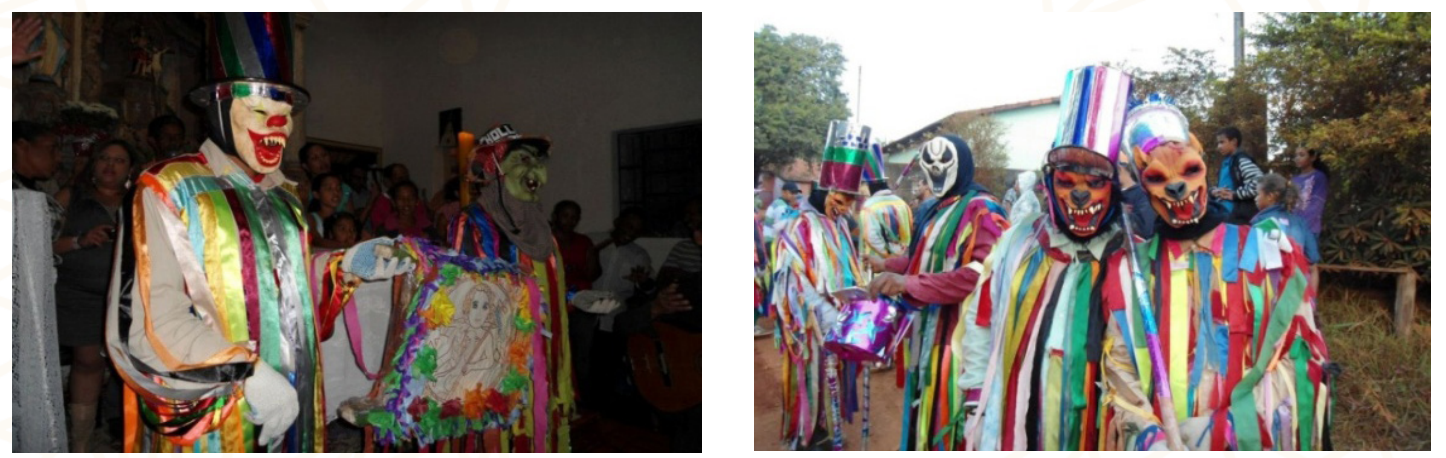

Figura 3 - Caretadas de São João. Corpos em estado alterado para a celebração da fé.

E, finalmente, dentre as inúmeras manifestações localizadas na região, a que tem um contingente maior de seguidores é, indiscutivelmente, a das folias. Eu tenho investigado as Folias do Divino Espírito Santo desde 1999, e a cada ano eu tenho notícia de pelo menos um novo cortejo. As Folias estão em todos os lugares. Na própria capital federal, nas pequenas comunidades de seu entorno e no meio rural, tanto de Goiás quanto de Minas Gerais. Existem folias do Divino, de Santos Reis, de São Sebastião, de Nossa Senhora d'Abadia, de São João, de Nossa Senhora Aparecida e várias outras. Em que consistem essas folias contemporâneas? São cortejos rogatórios, votivos e precatórios, que seguem um roteiro pré-estabelecido, com pousadas em sítios e fazendas, durante as noites, geralmente em torno de 12 , e visitas rápidas às casas dos moradores das vizinhanças durante o dia. E o que as Folias têm em comum com as outras manifestações é exatamente a profusão de imagens, quase todas elas associadas aos corpos de seus seguidores. 
Como exceção a essa dicotomia estabelecida entre uma sagração pela arquitetura e outra, pelos corpos dos fazedores, eu cito o caso do Vale do Amanhecer, uma comunidade localizada próximo à antiga Planaltina, no DF. É ali, talvez, onde se encontra a manifestação da região que mais aproxima uma proposta arquitetônica, radicalmente voltada para a adoração às divindades, com corpos em estados alterados e em total performatividade. Tia Neiva, sua mentora, seguiu, para a construção dos templos e para a caracterização de cada uma das legiões de seus seguidores, orientações de guias espirituais, o que fez do lugar um espaço totalmente diferenciado de tudo que se vê em Brasília (Figura 4).
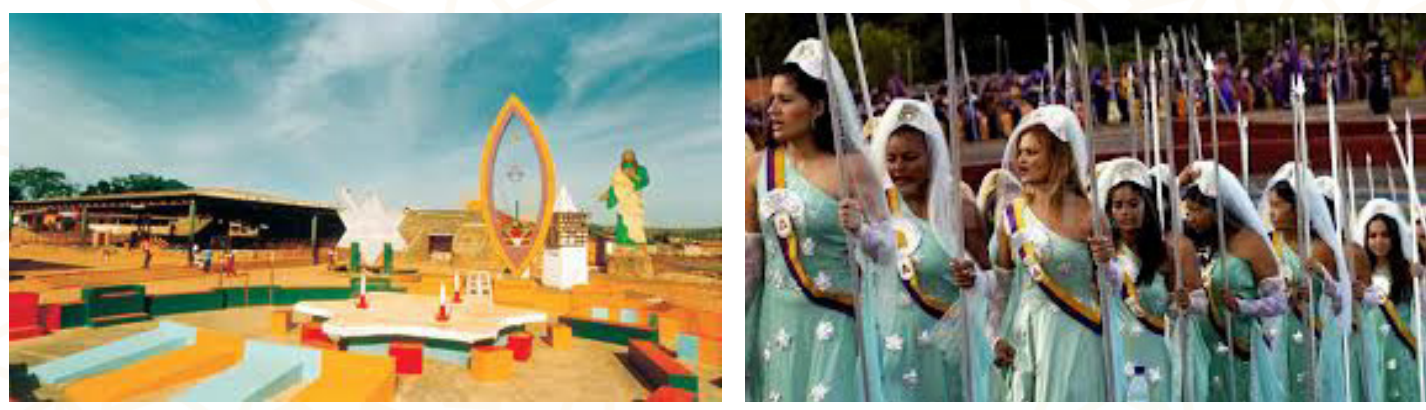

Figura 4 - Vale do Amanhecer. Arquitetura e corpos em estado alterado numa mesma manifestação de fé.

O que estou então ressaltando são o sentido e a força com que diversos ritos espetaculares que existiam antes, apesar da pregação de apagamento dessa memória antiga, insistem em permanecer e a cada dia tomar mais força. E eu ainda não falo da potência das Cavalhadas de Pirenópolis, também durante os festejos do Divino Espírito Santo, e das Cavalgadas, nova prática que se dissemina de forma impressionante em todo o meio rural, e mesmo em diversas aglomerações urbanas, de maior ou menor porte.

Assim, nos processos de transculturação pelos quais passam todos os grupos sociais quando entram em contato com outras maneiras de percepção de mundo, como o que ocorre no ambiente em que se consolida a Brasília dos ideais modernistas, é natural que ecoe sempre um grito de resistência. Nem sempre esse grito, porém, é de negação do novo. Muitas vezes, como eu compreendo que ocorre com as culturas pré-brasilienses da região, é somen- 
te a demanda pelo direito de continuar existindo, mesmo com a incorporação de valores, éticos e estéticos, dos colonizadores.

Então, por meus pensares, o que dá sentido a toda essa mobilização de cortejos, procissões e encontros sagracionais, ou não, está ligado a certo sentimento de não pertencimento que o discurso modernista da nova capital provoca em muitos de seus habitantes ou dos moradores das regiões vizinhas. Mesmo compreendendo que são sujeitos de diversas identificações, inclusive nas suas convivências sociais na própria Brasília, é muito comum ouvir, em suas falas, que a cidade é fria, dificulta os encontros, em outras palavras, desterritorializa. Esses ritos espetaculares, então, Ihes trazem o sentimento de que pertencem a um determinado lugar, onde podem, por desejo próprio, criar, recriar ou fazer permanecer suas práticas expressivas. O que é sempre alentador para os homens e mulheres que compreendem o significado de ouvir a grama crescer, vivendo o ordinário e o extraordinário de seu cotidiano, sempre feito dos melhores sabores. Esses melhores sabores são produzidos de saberes trocados naquilo que dá sentido às suas vidas, na capacidade de reinventar práticas de si baseadas no que de verdade Ihes importa: o fundante e intransferível direito de estar juntos. Inclusive com aqueles outros que, na defesa de novas narrativas, mesmo sem o perceber, naturalmente os tornam invisíveis.

\section{Referências bibliográficas}

COSTA, L. Arquitetura. Rio de Janeiro: Bloch/Fename, 1980.

DURAND, G. A imaginação simbólica. Tradução Liliane Fitipaldi. São Paulo: Cultrix/ Edusp, 1988.

ELIADE, M. O sagrado e o profano: a essência das religiões. Tradução Rogério Fernandes. São Paulo: Martins Fontes, 2001.

FREIRE, J. M.; REIS JÚNIOR, D. F. C. Um estudo sobre a identidade mística de Brasília - DF. Revista Geográfica da América Central, v. 2, n. 47E, 2011. Disponível em: <www.revistas.una.ac.cr/index.php/geografica/article/view/2702>. Acesso em: 7 fev. 2016.

HOLSTON, J. A cidade modernista: uma crítica de Brasília e sua utopia. Tradução Marcelo Coelho. São Paulo: Companhia das Letras, 1993.

KERN, I. De Aknaton a JK: das pirâmides a Brasília. Brasília, DF: Ipiranga, 1984. 
MEMORIAL JK. O sonho de Dom Bosco. 2014. Disponível em: <http://www.memorialjk.com.br/bsb/pgs/sonhodb.htm>. Acesso: 7 fev. 2016.

ROSA, G. S. Em entrevista. 25 maio 2003.

SIQUEIRA, D.; BANDEIRA, L. O profano e o sagrado na construção da "terra prometida". In: NUNES, B. F. (Org.). Brasília: a construção do cotidiano. Brasília, DF: Paralelo 15, 1997.

Recebido em 22/03/2016

Aprovado em 17/05/2016

Publicado em 01/07/2016 